\title{
Medication Adherence, Persistence and Cost in Multiple Sclerosis Patients: Oral vs Parenteral Treatment
}

Fiorenzo Santoleri ${ }^{\star}$, Ruggero Lasala, Andrea Logreco, Magda El Hassani and Alberto Costantini Department of Pharmacy, AUSL Pescara, Via Renato Paolini 47, 65124 Pescara, Italy

\section{Abstract}

The primary purpose of this study was to evaluate the medication adherence of MS patients to oral and parenteral self-administration therapy. The secondary outcome was to study how the adherence varies respect of the length of treatment and calculate the daily cost of therapy. The adherence was evaluated by the ratio between the Received Daily Dose (RDD) and the Prescribed Daily Dose (PDD); the persistence to treatment was plotted with the Kaplan Meier method. The daily cost of theraphy was calculated as cost per RDD. The adherence in function of time was calculated using 30 days intervals. The average adherence values were 0.91 for Avonex, 0.81 for Rebif ${ }^{\oplus}, 0.83$ for Betaferon ${ }^{\circ}, 0.81$ for Extavia ${ }^{\circ}$, 0.90 for Copaxone ${ }^{\oplus}, 0.89$ for Gilenya ${ }^{\circ}, 0.83$ for Aubagio ${ }^{\circ}$. The persistence on 3 years of therapy was $64 \%$ for Rebif ${ }^{\oplus}, 62 \%$ for Betaferon ${ }^{\circledR}, 58 \%$ for Gilenya ${ }^{\oplus}, 48 \%$ for Copaxone ${ }^{\oplus}, 45 \%$ for Avonex. As regards the variation of adherence in function of time, it shows up that after a year of treatment, the adherence values was stabilized at about 0.9 for Gilenya ${ }^{\oplus}$, Copaxone ${ }^{\circ}$ and Avonex, and between 0.8 and 0.85 for Rebif $^{\oplus}$, Betaferon ${ }^{\star}$ and Extavia ${ }^{\circ}$. The cost of the daily treatment ranges from a minimum of $€ 13.66$ for Betaferon to a maximum of $44 €$ for Gilenya ${ }^{\oplus}$. The comparison of oral therapy and the injection one showed no significant differences, underlining that in the case of Multiple Sclerosis, oral formulation does not represent a parameter in favour of the adherence to treatment. To equal levels of adherence it is not justifiable the higher cost of fingolimod compared to all other analysed treatments.

\section{Introduction}

Multiple sclerosis (MS) is a chronic inflammatory disease of the central nervous system that causes disability in population $[1,2]$. MS has a variable prevalence that oscillates from high levels in North America and Europe (> 100/100000 people) to lower ones in Western Asia and Sub-Saharan Africa (2/100000 people) [3]. The age of onset of disease is between 20 and 40 years, even if about 85 per cent of those who are newly diagnosed have a relapsein MS [4,5]. Four disease types can be recognised: relapsing-remitting MS (RRMS), primary-progressive, secondary-progressive, progressive-relapsing MS and clinically isolated syndrome (CIS) [6]. The approved drugs for MS treatment decrease the frequency of relapsing and delay the progression of disability [7]. The drugs currently in use are the diseasemodifying drugs (DMDs): interferon beta $1 \mathrm{~b}$ (SC) (Betaferon", Extavia $\left.^{\circledR}\right)$, [8] interferon beta 1a $\left[\operatorname{Avonex}^{\circledR}(\mathrm{IM}), \operatorname{Rebif}^{\circ}(\mathrm{SC})\right][9,10]$. Glatiramer Acetate (SC) $\left(\right.$ Copaxone $\left.{ }^{\star}\right),[11,12]$ fingolimod (Oral) $\left(\right.$ Gilenya $\left.^{\star}\right)$, [13-15] teriflunomide (Oral) $\left(\right.$ Aubagio $\left.^{\circ}\right),[16,18]$. (Oral) dimethyl fumarate $\left(\right.$ Tecfidera ${ }^{\oplus}$ ) [19], natalizumab (Tysabri ${ }^{\bullet}$ (EV), [20] peginterferon beta 1a (SC) $\left(\right.$ Plegridy $^{\circ}$ ) [21]. Clinical benefits by using these drugs are evident, but there are many problems related to administration pattern and to therapy chronicity $[22,23]$, especially for self-administration. These parameters influence the adherence and the efficacy medication [24-27]. Especially for the chronic condition the medication adherence is affected by routine of theraphy. The World Health Organization defined poor adherence to medication prescribed as a global problem that can lead to increase morbidity and mortality [28]. The non-adherence ratio to DMDs for MS was investigated and several results were published. Treadaway et al. found that $40 \%$ of patients were non-adherent in the first 4 weeks [29] . Other studies described that the discontinuation rate for IFN- $\beta$ and Glatiramer was from $17 \%$ to $46 \%$ in 4 years real world setting [3033]. When the adherence was investigated with patient questionnaire the values seem higher than obtained with other method. In fact the adherence ratio was higher of $80 \%$. [34, 35] This value is similar when the adherence was calculated as Proportion of days covered (PDC) $[36,37]$. The primary outcome of this study was the analysis of medication adherence, the persistence to treatment, the changing of adherence in function of persistence and the $\%$ of therapeutic switch in patients affected by MS. The secondary outcome was to evaluate the cost per RDD per drug by comparing the oral treatment with parenteral one.

\section{Subjects and Method}

This cross-sectional study was carried out in the hospital pharmacy of Pescara. All the patients affected by MS from the 1st January 2007 to the 31st December 2015 were involved in the study. The drugs analysed were Avonex ${ }^{\circ}$, Rebif ${ }^{\circ}$, Betaferon ${ }^{\circ}$, Extavia ${ }^{\circ}$, Copaxone ${ }^{\circ}$, Gilenya $^{\oplus}$. Aubagio ${ }^{\circ}$ and Tecfidera ${ }^{\circledR}$ were been considered for only analysis of switching because they are been introduced in market recently. According to the Italian law, no ethical approvals required to perform this type of analysis and no informed consent from patients is needed. At every single refill, for all patients the hospital pharmacists recorded the following parameters on "pharmadd.it", a software created ad hoc for drug-utilization studies: name, surname, age, sex, drug, date of refill, refilled quantity and therapeutic switch. Only patients in treatment at least six months were considered. The medication adherence has been calculated by using the method of ratio between weighted average of Received Daily Dose (RDD) and Prescribed Daily Dose (PDD) [38]. The RDD represents the ratio between the dose refilled and the number of days elapsed between two subsequent refills $[39,40]$. The PDD is the dose prescribed by the clinician $[41,42]$. The cost per RDD is estimated according to the ratio

"Corresponding Author: Dr. Fiorenzo Santoleri, Department of Pharmacy, AUSL Pescara, Via Renato Paolini 47, 65124 Pescara, Italy, Tel: 393493635174; E-mail: fiorenzosantoleri@hotmail.com

Citation: Santoleri F, Lasala R, Logreco A, Hassani ME, Costantini A (2016) Medication Adherence, Persistence and Cost in Multiple Sclerosis Patients. Oral vs Parenteral Treatment. Int J Pharma Sci Res 3: 117. doi: https://doi. org/10.15344/2394-1502/2016/117

Copyright: (C) 2016 Santoleri et al. This is an open-access article distributed under the terms of the Creative Commons Attribution License, which permits unrestricted use, distribution, and reproduction in any medium, provided the original author and source are credited. 
Citation: Santoleri F, Lasala R, Logreco A, Hassani ME, Costantini A (2016) Medication Adherence, Persistence and Cost in Multiple Sclerosis Patients. Oral vs Parenteral Treatment. Int J Pharma Sci Res 3: 117. doi: https://doi.org/10.15344/2394-1502/2016/117

Page 2 of 6

between the cost sustained by the Local Health Unit and the unit of measure as indicated by Defined daily dose (DDD), as well as below.

\section{COSTPERRDD $=\frac{\text { COST OF MEDICINE BOX }}{\text { COST OF MEDICINE BOX }} *$ RDD}

The rate of adherence in function of time was calculated by doing the average of the adherence of individual patients at 30-day intervals and plotted by placing the time factor on the abscissa axis and the adherence on ordinates axis.

\section{Analysis}

In descriptive analysis, pairwise comparisons using $t$ tests, Chisquared tests and log Rank test were conducted comparing curves of persistence and adherence. $\mathrm{P}$ values were compared with an a priori alpha 0.05 to determine statistical significance. Analysis were conducted with Graph pad prism 6.0.

\section{Results}

The number of patients, average age, sex, cost per RDD, and the medication adherence about the drug are in table 1. 229 patients were analysed treated with all the drugs included in the study from a minimum of 20 patients for teriflunomide to a maximum of 94 for interferon beta 1a shared between Avonex ${ }^{\circledR}$ (45,75\%) and Rebif ${ }^{\circledR}$. Average age oscillates between a minimum of 41 years to a maximum of 51, with values that varies from 20 to 69 years. Female population isthe most affected with an average ratio of $1 / 3$. Weighted average of RDD and PDD were calculated for every drug (Table 2). It is shown the DDD tabulated for all the drugs included in the study in order to estimate the difference with the prescribed dose.
In table 3 were described the therapeutic switches underlining the $\%$ of second line medications. The $\%$ of discontinuation of treatments varies from a minimum of $10 \%$ for teriflunomide to a maximum of $51.16 \%$ for Avonex ${ }^{\circ}$. The $40.91 \%$ of patients leave the therapy with Avonex to use Rebif demonstrating the importance to increase the dose. In fact the patients move from a PDD of $4.29 \mu \mathrm{g}$ to $18.53 \mu \mathrm{g}$ triplicating the daily dose. Switching to a second line treatment it is motivated by the loss of effectiveness of the first line one [43] and occurrence of side effects. The patient treated with Rebif ${ }^{\oplus}$, Betaferon ${ }^{\circ}$ and Extavia ${ }^{\circ}$ switched treatment in favour of the oral therapy with a per cent of $25.49,28.57$ and $14.29 \%$, respectively. Those treated with Copaxone $^{\infty}$ have switched for the $28 \%$ of which $50 \%$ in favour of oral therapies. That switch over to a greater effectiveness of the new oral administration drugs $[44,45]$ also has an higher acceptability by the patient and a greater adherence [46, 47]. The levels of adherence to treatment are shown in figure 1 and oscillate between a minimum of 0.81 for Extavia ${ }^{\oplus}$ and a maximum of 0.91 to Avonex ${ }^{\oplus}$. The persistence to treatment for the study drugs calculated at 3 years is plotted in figure 2. There were not significant differences between all drugs analysed (Logranktest, 95\% CI, Chisquare 1.057, P value: 0.3039 ). The drugs with a greater persistence were Rebif ${ }^{\oplus}$ and Extavia ${ }^{\circ} /$ Betaferon $^{\circ}$ with a $\%$ of the 64 and 62 , respectively. Following Gilenya ${ }^{\circ}$, Copaxone ${ }^{\circ}$ and Avonex ${ }^{\circ}$, respectively with values of 59,40 and $45 \%$. The ratio between adherence and persistence is plotted in figure 3 . The analysis was conducted in 3 years. There was significant difference between the Avonex ${ }^{\circ}$ curves and the others drugs. ( $\mathrm{t}$-test, 95\% CI, P value < 0.0001) The drug with the best ratio is Avonex ${ }^{\bullet}$ that never presents values below $90 \%$, while Rebif ${ }^{\star}$ has the worst profile, with adherence values always below $85 \%$. Finally, the costs per RDD were calculated for the analysed drugs and it oscillates between a minimum of $€ 13.66$ for Betaferon ${ }^{\circledR}$ to a maximum of $44 €$ for Gilenya ${ }^{\oplus}$.

\begin{tabular}{|c|c|c|c|c|c|c|c|}
\hline \multicolumn{8}{|c|}{ Baseline characteristcs and outcomes } \\
\hline & \multicolumn{7}{|c|}{$>180$ days } \\
\hline & \multicolumn{5}{|c|}{ Parenteral } & \multicolumn{2}{|c|}{ Oral } \\
\hline & \multicolumn{2}{|c|}{ Interferon beta 1a } & \multicolumn{2}{|c|}{ Interferon beta $1 \mathrm{~b}$} & \multirow{2}{*}{$\begin{array}{l}\text { Glatiramer } \\
\text { Copaxone }^{\circ}\end{array}$} & \multirow{2}{*}{$\begin{array}{l}\text { Fingolimod } \\
\text { Gilenya }^{\bullet}\end{array}$} & \multirow{2}{*}{$\begin{array}{l}\text { Teriflunomide } \\
\text { Aubagio }^{\circ}\end{array}$} \\
\hline & Avonex ${ }^{\circ}$ & Rebif ${ }^{\infty}$ & Betaferon ${ }^{\circ}$ & Extavia $^{\circ}$ & & & \\
\hline $\mathrm{N} \wedge^{\wedge}$ pat & 43 & 51 & 14 & 14 & 50 & 37 & 20 \\
\hline $\begin{array}{l}\text { Median age in years } \\
\text { Min - Max }\end{array}$ & $\begin{array}{l}48 \\
20-65\end{array}$ & $\begin{array}{l}41 \\
22-65\end{array}$ & $\begin{array}{l}45 \\
24-66\end{array}$ & $\begin{array}{l}51 \\
38-69\end{array}$ & $\begin{array}{l}45.5 \\
21-68\end{array}$ & $\begin{array}{l}46 \\
24-57\end{array}$ & $\begin{array}{l}48.5 \\
32-67\end{array}$ \\
\hline Male gender, \% & 23.26 & 27.45 & 42.86 & 42.86 & 30 & 21.66 & 40 \\
\hline WRDD (SD) & $3.97(0.62)$ & $14.53(4.46)$ & $3.32(0.85)$ & $3.24(0.85)$ & $18.09(3.27)$ & $0.45(0.07)$ & $11.72(2.32)$ \\
\hline Cost per RDD $(€)$ & 22.82 & 37.97 & 13.66 & 14.17 & 21.51 & 44.00 & 21.89 \\
\hline WADH (SD) & $0.91(0.13)$ & $0.81(0.19)$ & $0.83(0.21)$ & $0.81(0.21)$ & $0.90(0.15)$ & $0.89(0.13)$ & $0.83(0.16)$ \\
\hline WADH male (SD) & $0.90(0.16)$ & $0.86(0.14)$ & $0.91(0.12)$ & $0.77(0.30)$ & $0.93(0.08)$ & $0.94(0.05)$ & $0.79(0.19)$ \\
\hline WADH female (SD) & $0.92(0.12)$ & $0.79(0.21)$ & $0.77(0.25)$ & $0.84(0.13)$ & $0.88(0.18)$ & $0.88(0.19)$ & $0.86(0.14)$ \\
\hline
\end{tabular}

Table 1: Patients, Median Age, Sex, Weighted Received Daily Dose(WRDD), Cost per RDD, Weighted Medication Adherence.

\begin{tabular}{|c|c|c|c|c|c|c|c|}
\hline & \multicolumn{5}{|c|}{ Parenteral } & \multicolumn{2}{|c|}{ Oral } \\
\hline & \multicolumn{2}{|c|}{ Interferon beta $1 \mathrm{a}$} & \multicolumn{2}{|c|}{ Interferon beta $1 \mathrm{~b}$} & \multirow{2}{*}{$\begin{array}{l}\text { Glatiramer } \\
\text { Copaxone }^{\circledast}\end{array}$} & \multirow{2}{*}{$\begin{array}{l}\text { Fingolimod } \\
\text { Gilenya }^{\circledR}\end{array}$} & \multirow{2}{*}{$\begin{array}{l}\text { Teriflunomide } \\
\text { Aubagio }^{\circ}\end{array}$} \\
\hline & Avonex $^{\infty}$ & Rebif $^{\infty}$ & Betaferon ${ }^{\circledR}$ & Extavia $^{\infty}$ & & & \\
\hline DDD & 4.3 & & 4 & & 20 & 0.5 & 14 \\
\hline WPDD & 4.29 & 18.53 & 4 & 4 & 20 & 0.5 & 14 \\
\hline WRDD (SD) & $3.97(0.62)$ & $14.53(4.46)$ & $3.32(0.85)$ & $3.24(0.85)$ & $18.09(3.27)$ & $0.45(0.07)$ & $11.72(2.32)$ \\
\hline
\end{tabular}

Table 2: Defined Daily Dose (DDD), Weighetd Prescribed Daily Dose (WPDD), Weighted Received Daily Dose (WRDDD) divided by drugs. 
Citation: Santoleri F, Lasala R, Logreco A, Hassani ME, Costantini A (2016) Medication Adherence, Persistence and Cost in Multiple Sclerosis Patients. Oral vs Parenteral Treatment. Int J Pharma Sci Res 3: 117. doi: https://doi.org/10.15344/2394-1502/2016/117

Page 3 of 6

\begin{tabular}{|c|c|c|c|c|c|c|c|c|c|}
\hline In & & \multirow[t]{2}{*}{ Avonex $^{\infty}$} & \multirow[t]{2}{*}{ Rebif $^{\infty}$} & \multirow[t]{2}{*}{ Betaferon $^{\infty}$} & \multirow[t]{2}{*}{ Extavia $^{\oplus}$} & \multirow[t]{2}{*}{ Copaxone ${ }^{\infty}$} & \multirow[t]{2}{*}{ Gilenya $^{\infty}$} & \multirow[t]{2}{*}{ Aubagio $^{\infty}$} & \multirow[t]{2}{*}{ Tecfidera $^{\star}$} \\
\hline Out & $\%$ & & & & & & & & \\
\hline Avonex $^{\infty}$ & 51.16 & & 40.91 & 4.55 & & 13.64 & 22.73 & & 18.18 \\
\hline Rebif & 25.49 & & & & & 16.67 & 50.00 & 8.33 & 25.0 \\
\hline Betaferon $^{\infty}$ & 28.57 & & & & & & & 50.00 & 50.00 \\
\hline Extavia $^{\infty}$ & 14.29 & & & & & & & 50.00 & 50.00 \\
\hline Copaxone $^{\oplus}$ & 28.00 & & 12.5 & & 12.5 & & 25.00 & 25.00 & 25.00 \\
\hline Gilenya & 10.81 & & & & & & & 50.00 & 50.00 \\
\hline Aubagio $^{\circ}$ & 10.00 & & & & & & 50.00 & & 50.00 \\
\hline
\end{tabular}

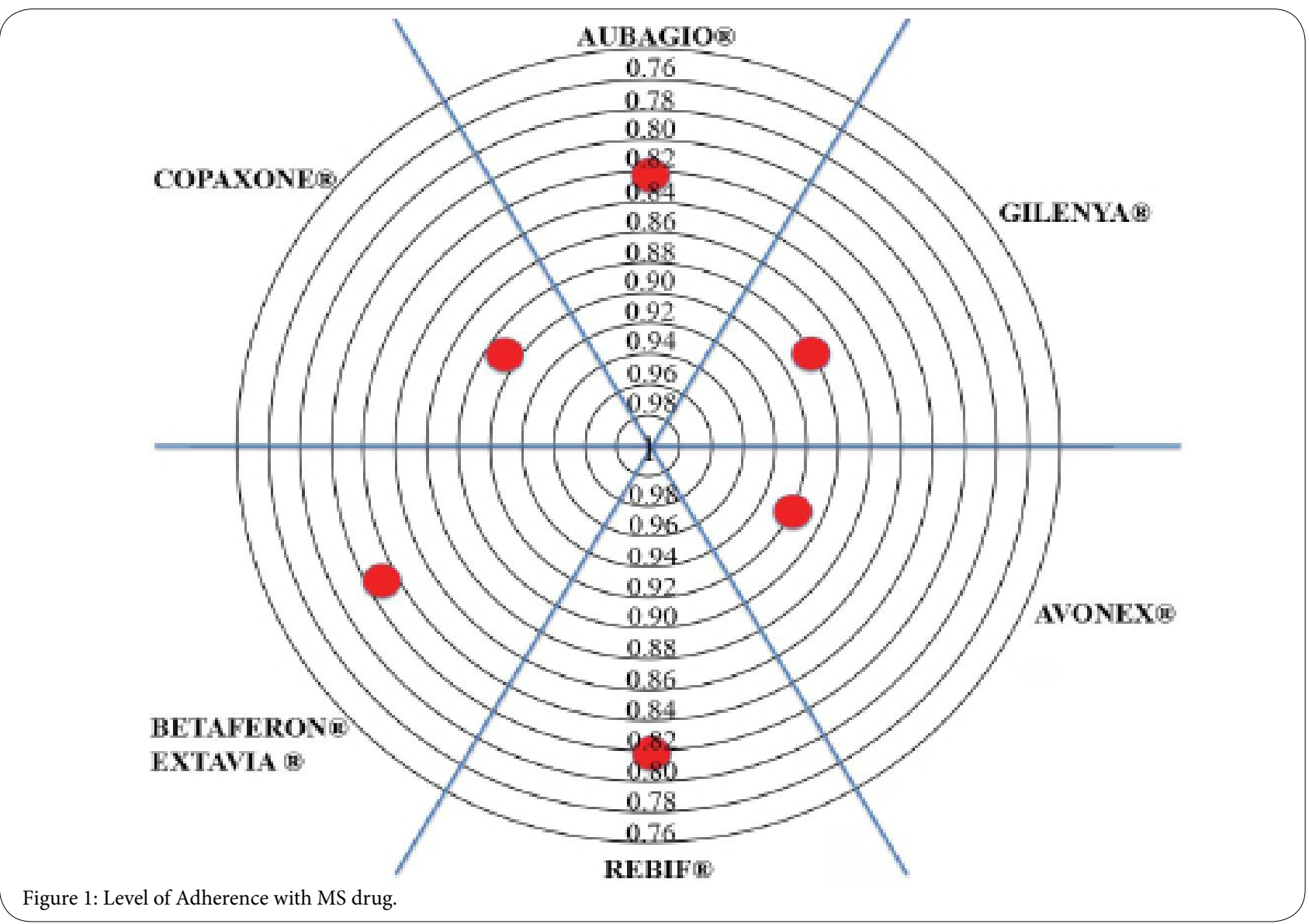

\section{Discussions}

In observational analyses of administrative claims data, medication adherence is measured frequently with a medication possession ratio (MPR) or proportion of days covered (PDC). These variables measure the time in days in which the patient is covered by drugs. [48] The days covered of drug are linked to standard dose, DDD, according the following formula:

days covered $=\frac{\text { Total dose dispensed }}{D D D\left(\begin{array}{l}\text { Dose } \\ \text { Day }\end{array}\right)}$

As reported by Sinnot et al., the use of DDDs to evaluate the medication adherence can overestimate or underestimate the drug exposure according to the pathology analysed. [49] The DDD does not represent the physician intention to treat and is possible to use it to evaluate medication adherence only when coincides with PDD.
In this study medication adherence is evaluated using the parameter of drug utilization RDD and PDD. RDD describes the patient behaviour to therapy (administration) while PDD represents the dose prescribed by the clinician. In many cases the PDD coincides with the DDD that represents the average dose of medication to be taken daily for the primary indication [50]. In the case of MS, as shown in Table 3, the PDD coincides with the DDD for all drugs except interferon beta 1 a. For Avonex ${ }^{\oplus}$ DDD matches with PDD while Rebif is about three times higher. For this reason, both in adherence calculation and in the calculation of the cost of treatment is most appropriate to consider the PDD that provides a more reliable parameter and adherent to reality. From the calculation of adherence to treatment the drug with the best profile is Avonex ${ }^{\oplus}$. This result can be explained by a simpler dosing regimen with an administration every 7 days compared to other drugs both administrated parenteral and orally. From this analysis, adherence to oral therapy is similar or lower than the parenteral one, Gilenya ${ }^{\oplus} 0.89$ - Aubagio ${ }^{\circ} 0.83$ vs. 0.81 Rebif, 0.93 Avonex, 0.82 Betaferon / Extavia ${ }^{\circ}$, 0.90 Copaxone ${ }^{\oplus}$. 
Citation: Santoleri F, Lasala R, Logreco A, Hassani ME, Costantini A (2016) Medication Adherence, Persistence and Cost in Multiple Sclerosis Patients. Oral vs Parenteral Treatment. Int J Pharma Sci Res 3: 117. doi: https://doi.org/10.15344/2394-1502/2016/117

Page 4 of 6
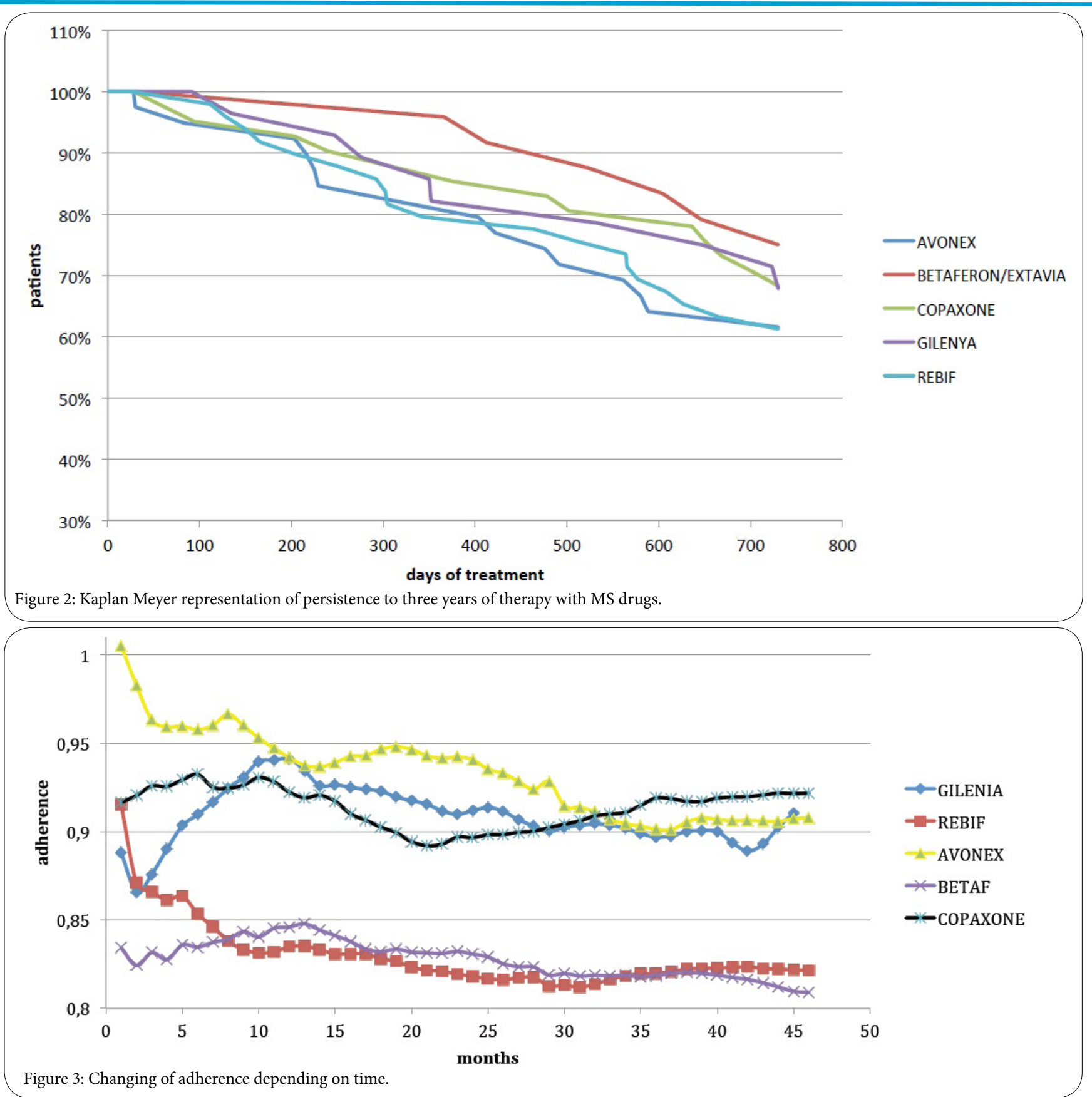

The adherence rate of DMDs were similar to the published one [51,52]. Considering the differences in terms of adherence and persistence, the profile of oral therapy is comparable to parenteral one, the only discriminant is represented by the daily cost as cost per RDD where the fingolimod has a considerably higher cost than the other in the study. Another important aspect in chronic therapies and especially in MS is the therapeutic switches that may have different motivations, from therapeutic failure to improve patient compliance. [53] The 51\% of patients leaves the Avonex to move to Rebif ${ }^{\oplus}$. Considering that Avonex has an higher adherence compared to Rebif ${ }^{\circ}$, the passage can be motivated by the loss of effectiveness and the need to treat patients with higher doses, changing the dosing regimen and influencing the adherence to the treatment. Talking about the oral administration there is a massive shift in favour of fingolimod clinically justified by a greater effectiveness $[54,55]$ but not by a better adherence, which in fact tends to be affected by the time function, as shown in figure 3. The adherence profile in function of persistence shows a steady increase from $89 \%$ in the first month to $94 \%$ in the twelfthone before falling steadily.This aspect could be explained by the repetitiveness of daily oral administration which tends to become monotonous and therefore it causes a loss of adherence over time.

\section{Conclusions}

From the analysis conducted on the use of disease modifying drugs used in MS therapy, it results a good adherence for all the analysed drugs. There is a management problem of therapy that is underlined by the switch of the therapy and the persistence to treatment. The better adherence profile of Avonex compared all drugs shows as the dosing schedule (once weekly) increase the terms of adherence. 
Citation: Santoleri F, Lasala R, Logreco A, Hassani ME, Costantini A (2016) Medication Adherence, Persistence and Cost in Multiple Sclerosis Patients. Oral vs Parenteral Treatment. Int J Pharma Sci Res 3: 117. doi: https://doi.org/10.15344/2394-1502/2016/117

From the pharmacoeconomic analysis, calculated considering only the cost of the drug based on the actual use, it results a two fold cost of fingolimod compared to oral and parenteral competitor that does not seem to be justified considering the use of other therapeutic options with oral administration.

\section{Study Limitations}

Limitations include small sample sizes, single-centerstudies, and geographically restricted populations.

\section{Competing Interests}

The authors declare that they have no conflict of interest in this work.

\section{References}

1. Tullman MJ (2013) Overview of the epidemiology, diagnosis, and disease progression associated with multiple sclerosis. Am J Manag Care 19: S1520.

2. Dutta R, Trapp BD (2014) Relapsing and progressive forms of multiple sclerosis: insights from pathology. Curr Opin Neurol 27: 271-278.

3. Leray E, Moreau T, Fromont A, Edan G (2015) Epidemiology of multiple sclerosis. Rev Neurol (Paris). 172: 3-13.

4. Loma I, Heyman R (2011) Multiple sclerosis: pathogenesis and treatment Curr Neuropharmacol 9: 409-416.

5. Compston A, Coles A (2008) Multiple sclerosis. Lancet 372: 1502-1517.

6. Milo R, Miller A (2014) Revised diagnostic criteria of multiple sclerosis Autoimmun Rev 13: 518-524.

7. Martinelli Boneschi F, Vacchi L, Rovaris M, Capra R, Comi G, et al. (2013) Mitoxantrone for multiple sclerosis. Cochrane Database Syst Rev 4 CD002127.

8. Kappos L, Polman CH, Freedman MS, Edan G, Hartung HP, et al. (2006) Treatment with interferon beta-1b delays conversion to clinically definite and McDonald MS in patients with clinically isolated syndromes. Neurology 67: $1242-1249$

9. [No authors listed] (1998) PRISMS Study Group Randomized doubleblind placebo-controlled study of interferon beta-1a in relapsing/remitting multiple sclerosis. Lancet 352: 1498-1504.

10. Jacobs LD, Cookfair DL, Rudick RA, Herndon RM, Richert JR, et al. (1996) Intramuscular interferon beta-1a for disease progression in relapsing multiple sclerosis. The Multiple Sclerosis Collaborative Research Group (MSCRG). Ann Neurol 39: 285-294.

11. Ge Y, Grossman RI, Udupa JK, Fulton J, Constantinescu CS, et al. (2000) Glatiramer acetate (Copaxone) treatment in relapsing-remitting MS: quantitative MR assessment. Neurology 54: 813-817.

12. Bains SN, Hsieh FH, Rensel MR, Radojicic C, Katz HT, et al. (2010) Glatiramer acetate: successful desensitization for treatment of multiple sclerosis. Ann Allergy Asthma Immunol 104: 321-325

13. Kappos L, Radue EW, O'Connor P, Polman C, Hohlfeld R, et al. (2010) A placebo-controlled trial of oral fingolimod in relapsing multiple sclerosis. $\mathrm{N}$ Engl J Med362: 387-401.

14. Cohen JA, Chun J (2011) Mechanisms of fingolimod's efficacy and adverse effects in multiple sclerosis. Ann Neurol 69: 759-777.

15. Gajofatto A, Turatti M, Monaco S, Benedetti MD (2015) Clinical efficacy, safety, andtolerability of fingolimod for the treatment of relapsing-remitting multiplesclerosis. Drug Healthc Patient Saf 7: 157-167.

16. O'Connor PW, Li D, Freedman MS, Bar-Or A, Rice GP, et al. (2006) A Phase II study of the safety and efficacy of teriflunomide in multiple sclerosis with relapses. Neurology 66: 894-900.

17. O'Connor P, Wolinsky JS, Confavreux C, Comi G, Kappos L, et al. (2011) Randomized trial of oral teriflunomide for relapsing multiple sclerosis. $\mathrm{N}$ Engl J Med 365: 1293-1303.

18. He D, Xu Z, Dong S, Zhang H, Zhou H, et al. (2012) Teriflunomide for multiple sclerosis. Cochrane Database Syst Rev 12: CD009882.
19. Kappos L, Gold R, Miller DH, Macmanus DG, Havrdova E, et al. (2008) Efficacy and safety of oral fumarate in patients with relapsing-remitting multiple sclerosis: a multicentre, randomised, double-blind, placebocontrolled phase Ilb study. Lancet 372:1463-1472.

20. Shirani A, Okuda DT, Stüve O3,4 (2016) Therapeutic Advances and Future Prospects in Progressive Forms of Multiple Sclerosis. Neurotherapeutics 13: 58-69.

21. Tolley K, Hutchinson M, You X, Wang P, Sperling B, et al. (2015) A Network Meta-Analysis of Efficacy and Evaluation of Safety of Subcutaneous Pegylated Interferon Beta-1a versus Other Injectable Therapies for the Treatment of Relapsing-Remitting Multiple Sclerosis. PLoS One 10: e0127960.

22. Klauer T, Zettl UK (2008) Compliance, adherence, and the treatment of multiple sclerosis. J Neurol 255 Suppl 6: 87-92.

23. Hutchinson M (2005) Treatment adherence: what is the best that can be achieved? Int MS J 12: 73.

24. Devonshire V, Lapierre Y, Macdonell R, Ramo-Tello C, Patti F, et al. (2011) The Global Adherence Project (GAP): a multicenter observational study on adherence to disease-modifying therapies in patients with relapsingremitting multiple sclerosis. Eur J Neurol 18: 69-77.

25. Río J, Porcel J, Téllez N, Sánchez-Betancourt A, Tintoré M, et al. (2005) Factors related with treatment adherence to interferon beta and glatiramer acetate therapy in multiple sclerosis. Mult Scler 11: 306-309.

26. Río J, Porcel J, Téllez N, Sánchez-Betancourt A, Tintoré M, et al. (2005) Factors related with treatment adherence to interferon beta and glatiramer acetate therapy in multiple sclerosis. Mult Scler 11: 306-309.

27. Girouard N, Soucy N (2011) Patient considerations in the management of multiple sclerosis: development and clinical utility of oral agents. Patient Prefer Adherence 5: 101-108.

28. World Health Organization (2010) Adherence to long-term therapies: Evidence for action.

29. Treadaway K, Cutter G, Salter A, Lynch S, Simsarian J, et al. (2009) Factors that influence adherence with disease-modifying therapy in MS. Neurol 256: 568-576.

30. Tremlett HL, Oger J (2003) Interrupted therapy: stopping and switching of the beta-interferons prescribed for MS. Neurology 61: 551-554.

31. O'Rourke KE, Hutchinson M (2005) Stopping beta-interferon therapy in multiple sclerosis: an analysis of stopping patterns. Mult Scler 11: 46-50.

32. Río J, Porcel J, Téllez N, Sánchez-Betancourt A, Tintoré M, et al. (2005) Factors related with treatment adherence to interferon beta and glatiramer acetate therapy in multiple sclerosis. Mult Scler 11: 306-309.

33. Portaccio E, Zipoli V, Siracusa G, Sorbi S, Amato MP (2008) Long-term adherence to interferon beta therapy in relapsing-remitting multiple sclerosis. Eur Neurol 59: 131-135.

34. Hupperts R, Becker V, Friedrich J, Gobbi C, Salgado AV, et al. (2015) Multiple sclerosis patients treated with intramuscular IFN-ß-1a autoinjector in areal-world setting: prospective evaluation of treatment persistence, adherence, quality of life and satisfaction. Expert Opin Drug Deliv 12: 1525.

35. Katsarava Z, Ehlken B, Limmroth V, Taipale K, et al. (2015) Adherence and cost in multiple sclerosis patients treated with IM IFN beta-1a: impact of the CARE patient management program. BMC Neurol 15: 170.

36. Kozma CM, Phillips AL, Meletiche DM (2014) Use of an early diseasemodifying drug adherence measure to predict future adherence in patients with multiple sclerosis. J Manag Care Spec Pharm 20: 800-807.

37. Evans C, Marrie RA, Zhu F, Leung S, Lu X, et al. (2016) Adherence and persistence to drug therapies for multiple sclerosis: A population-based study. Mult Scler Relat Disord 8: 78-85.

38. Santoleri F, Sorice P, Lasala R, Rizzo RC, Costantini A (2013) Patient adherence and persistence with Imatinib Nilotinib, Dasatinib in clinical practice. PLoS One 8: e56813.

39. Deambrosis P, Saramin C, Terrazzani G, Scaldaferri L, Debetto P, et al. (2007) Evaluation of the prescription and utilization patterns of statins in an Italian local health unit during the period 1994-2003. Eur J Clin Pharmacol 63: 197-203.

40. Roggeri D, Saramin C, Terrazzani G, Zusso M, Giusti P, et al. (2007) Resource consumption and costs of treating pain in patients affected by cancer in a district of northeast Italy. Pharmacol Res 56: 329-334. 
Citation: Santoleri F, Lasala R, Logreco A, Hassani ME, Costantini A (2016) Medication Adherence, Persistence and Cost in Multiple Sclerosis Patients. Oral vs Parenteral Treatment. Int J Pharma Sci Res 3: 117. doi: https://doi.org/10.15344/2394-1502/2016/117

41. Gagliotti C, Ricchizzi E, Buttazzi R, Tumietto F, Resi D, et al. (2014) Hospital statistics for antibiotics: defined versus prescribed daily dose. Infection 42: 869-873.

42. Grimmsmann T, Himmel W (2011) Discrepancies between prescribed and defined daily doses: a matter of patients or drug classes? Eur J Clin Pharmacol 67: 847-854.

43. Río J, Tintoré M, Sastre-Garriga J, Nos C, Castilló J, et al. (2012) Change in the clinical activity of multiple sclerosis after treatment switch for suboptimal response. Eur J Neurol 19: 899-904.

44. Giovannoni G, Southam E, Waubant E (2012) Systematic review of disease-modifying therapies to assess unmet needs in multiple sclerosis: tolerability and adherence. Mult Scler 18: 932-946.

45. Singer $B A(2013)$ Initiating oral fingolimod treatment in patients with multiple sclerosis. Ther Adv Neurol Disord 6: 269-275.

46. Bergvall N, Makin C, Lahoz R, Agashivala N, Pradhan A, et al. (2014) Relapse rates in patients with multiple sclerosis switching from interferon to fingolimod or glatiramer acetate: a US claims database study. PLoS One 9: e88472

47. Gasperini C, Cefaro LA, Borriello G, Tosto G, Prosperini L, et al. (2008) Emerging oral drugs for multiple sclerosis. Expert Opin Emerg Drugs 13: 465-477.

48. Cramer JA, Roy A, Burrell A, Fairchild CJ, Fuldeore MJ, et al. (2008) Medication compliance and persistence: terminology and definitions. Value Health 11: 44-47.

49. Sinnott SJ, Polinski JM, Byrne S, Gagne JJ (2016) Measuring drug exposure: concordance between defined daily dose and days' supply depended on drug class. J Clin Epidemiol 69: 107-113.

50. WHO Collaborating Centre for Drug Statistics Methodology (2015) Guidelines for ATC classification and DDD assignment 2015, Oslo.

51. Agashivala N, Wu N, Abouzaid S, Wu Y, Kim E, et al. (2013) Compliance to fingolimod and other disease modifying treatments in multiple sclerosis patients, a retrospective cohort study. BMC Neurol 13: 138

52. Fernández $\mathrm{O}$, Arroyo $\mathrm{R}$, Martínez-Yélamos $\mathrm{S}$, Marco $\mathrm{M}$, Merino JA, et al. (2016) Long-Term Adherence to IFN Beta-1a Treatment when Using RebiSmart $囚$ Device inPatients with Relapsing-Remitting Multiple Sclerosis. PLoS One 11: e0160313.

53. Markowitz CE (2015) Switching therapies in MS: what are the options? Clin Psychiatry 76: e6.

54. Singer $B A(2013)$ Initiating oral fingolimod treatment in patients with multiple sclerosis. Ther Adv Neurol Disord 6: 269-275.

55. Meng X, Chin PS, Hashmonay R, Zahur Islam M, Cutter G (2015) Effect of switching from intramuscular interferon $ß-1 a$ to oral fingolimod on time to relapse in patients with relapsing-remitting multiple sclerosis enrolled in a 1-year extension of TRANSFORMS. Contemp Clin Trials41: 69-74. 